\title{
Electrochemical Perforance and Synthesis of Nanostructured Lead Oxide
}

\author{
Huiqi Wang \\ School of Materials Science and Engineering, Tianjin Polytechnic University \\ Tianjin 300160, China \\ E-mail: hqiwang@163.com
}

\begin{abstract}
This paper describes a facial in situ synthesis method of nanostructured lead oxide powders. Lead oxide crystallites was reproducibly prepared by optimization of the temperature condition at $700^{\circ} \mathrm{C}$. The morphology, crystallization process, specific surface area and electrochemical performance of $\mathrm{PbO}$ was characteriazed by different analytical methods such as XRD, SEM, TEM, BET gas sorption specific surface area measurements and electrochemical tests. The XRD showed that the PbO is mixtures of $\alpha$ - and $\beta$ - phases. TEM observations indicated exhibited similar morphologies with micrometer sized irregular block shapes. The BET surface area of $\mathrm{PbO}$ powders is increased up to $11 \mathrm{~m}^{2} \mathrm{~g}^{-1}$. For such $\mathrm{PbO}$ powders applied as anode materials in Lead acid batteries, we have managed to retain a reversible capacity above $60 \mathrm{mAh} \mathrm{g}^{-1}$ beyond cycles.
\end{abstract}

Keywords: Nanostructured lead oxide, Electrochemical performance, Storage systems

\section{Intrdouction}

During the past decade, one-dimensional (1D) nanostructured materials have sparked a worldwide interest because of their unique electronic, optical, and mechanical properties and their potential applications in nanodevices and functional materials. As a consequence, highly anisotropic 1D nanostructures using various materials, such as elemental carbon, carbon-based substances, metals, oxides, sulfides, nitrides, etc have been fabricated through a variety of methods. Studies have shown that some of the physical properties exhibited by these nanostructures are different from those of the bulk crystals. Modern technology, nowadays, appears impossible without the use of different portable rechargeable batteries in various electronic devices. The Lead acid batteries are among the most promising ones, and comprehensive research on novel cathode or anode materials is going on all over the world. During the last few years, the application of nano-structured oxide materials as anodes in Lead acid batteries has attracted considerable attention. Among the different approaches the solid state synthesis appears to be a fast, versatile and industry scalable method that is able to produce in situ, various nano-structured oxides. This method is quite versatile and applicable for preparation of a large number of simple or complex oxides.

Recently, considerable research efforts have been directed toward the preparation of binary oxides with 1D nano-structures. However, to the best of our knowledge, studies that de-scribe the preparation of lead oxides with $1 \mathrm{D}$ nanostructures have been relatively few. Lead oxides, which include four basic types $\left(\mathrm{PbO}, \mathrm{Pb}_{2} \mathrm{O}_{3}, \mathrm{PbO}_{2}\right.$, and $\mathrm{Pb}_{3} \mathrm{O}_{4}$ ), have wide industrial applications due to their distinctive properties. In particular, $\mathrm{Pb}_{3} \mathrm{O}_{4}$ possesses interesting physical characteristics due to its mixed valence, resulting in its unique electronic structure. As we know, $\mathrm{PbO}_{2}$ and $\mathrm{Pb}_{3} \mathrm{O}_{4}$ are commonly used as electrodes in batteries. Huynh et al. showed that the operating properties of batteries depend not only on the structure, but also on the morphology of the electrode components. In this case, it was shown that $1 \mathrm{D}$ nanostructures are more prone to charge transport than the bulk crystalline structures. Currently, because of limited studies on $\mathrm{PbO}_{2}$ and $\mathrm{Pb}_{3} \mathrm{O}_{4} 1 \mathrm{D}$ nanostructures and their subsequent applications in nanoscale electronic devices, investigations on the size-dependent properties of lead oxides are significantly delayed. The in situ preparation of such nano-structured materials with controlled structural and morphological characteristics has both scientific and practical importance.

We believe that this synthetic methodology, which features the same reaction but under different conditions for each lead oxide, will be valuable toward research in the nanometer regime. Here, we report a novel simple one-step method to control the shape and morphology of a series of $\mathrm{PbO}$ nanostructures by direct oxidation of lead nitrate. This method provides a controllable, mild, and convenient approach for the preparation of $\mathrm{PbO}$ nano-structures without the sophisticated technique and catalysts. $\mathrm{PbO}$ nanosheets can be selectively synthesized on a large scale with reaction temperature.

\section{Experimental}

The nanostructured lead oxide was synthesized by the heat treatment of $\mathrm{Pb}\left(\mathrm{NO}_{3}\right)_{2}$ solid powder under nitrogen 
$\left(\mathrm{N}_{2}\right)$ in a tubular furnace up to $700^{\circ} \mathrm{C}$ for $3.5 \mathrm{~h}\left(10^{\circ} \mathrm{C} \mathrm{min}^{-1}\right)$.

\section{Measurements}

X-ray diffraction (XRD) patterns of the samples were obtained on a Bruker D8 Discover instrument operating at $40 \mathrm{kV}$ and $20 \mathrm{~mA}$, using CuKa radiation $(\mathrm{k}=0.15406 \mathrm{~nm})$. Transmission electron micrographs (TEM) of the samples were taken on a Hitachi H-7650 microscope operating at $80 \mathrm{kV}$. Adsorption measurements of the samples were performed by using auto adsorption apparatus -AUTO SORB-1 Surface Area \& Pore-Size Analyzer (Quantachrome Corporation, USA) by adsorption/desorption of nitrogen at $77 \mathrm{~K}$, after preheated at $300{ }^{\circ} \mathrm{C}$ for $4 \mathrm{~h}$ to remove moisture.

Cyclic voltammetry was carried out at room temperature using a LK3200 electrochemical workstation (Lanlike Instruments, Lanlike Corp., Tianjin, China) at a scanning rate of $10 \mathrm{mV} \mathrm{s}^{-1}$. A common three-electrode electrochemical cell was employed in these experiments. a $\mathrm{Ag} / \mathrm{AgCl}$ with the saturated $\mathrm{KCl}$ solution electrode and a Pt gauze as the reference and the counter electrode, respectively. A $3 \mathrm{~mm}$ carbon paste electrode(CPE) for working electrode was washed with water and acetone. The electrodes were prepared by mixing $85 \mathrm{wt} . \% \mathrm{PbO}$, $10 \mathrm{wt} . \%$ acetylene black as a conductive agent and $5 \mathrm{wt} . \%$ PTFE ( $60 \mathrm{wt} . \%$ solution) as a binder, and the mixture as mixed in agate mortar to obtain a homogeneous limber black solid, which was pasted on the pasting hole of $\mathrm{CPE}$, then dried at $60^{\circ} \mathrm{C}$. The electrolyte was a $4.0 \mathrm{M} \mathrm{H}_{2} \mathrm{SO}_{4}$ solution. The discharge-charge were conducted in the voltage range of 1.7-2.4V with a Battery Tester (Neware, Shenzhen, China) at the specific current of $1 \mathrm{~A} / \mathrm{g}$.

\section{Results and discussion}

The $\mathrm{PbO}$ was facilely prepared by decomposing starch and $\mathrm{Pb}\left(\mathrm{NO}_{3}\right)_{2}$ at high temperature. The $\mathrm{PbO}$ are mixtures of $\alpha$ - and $\beta$ - phases that revealed by powder X-ray diffraction (Figure 1). TEM observations indicated exhibited similar morphologies with micrometer sized irregular block shapes. (Figure 2).

Shown in Figure 3 adsorption isotherms for the lead oxide under study. One can observe their high similarity. There is a pronounced step related to the of micropore filling at relative pressures close to $10^{-5}$ and subsequently the dsorbed amount rises gradually with the pressure increase. After the relative pressure of about 0.1 is reached, the further rease in adsorption is relatively low (ca. 5-10\%), which ndicates low mesopore volume of the active carbons studied. Such a small amount of mesopores can be expected to rise to poor pore connectivity, which would manifest itself in long equilibration times during the adsorption run and/or the presence of a low pressure hysteresis loop is not the case for the active carbons in the current study, which suggests that the porous structures of the materials are readily accessible for the nitrogen adsorbate. The BET specific surface area for the $\mathrm{PbO}$ ranges from 7.0 to $11.0 \mathrm{~m}^{2} \mathrm{~g}^{-1}$.

Figure 4 shows the typical cyclic votammograms (CVs) of nanostructured $\mathrm{PbO}$ electrodes at a scan rate of $10 \mathrm{mV}$ $\mathrm{s}^{-1}$ in the voltage range between $-0.8-1.8 \mathrm{~V}$. The CV curves for lead oxide electrode clearly indicate the irreversible reaction during the first discharge with redox peaks,. The main redox processes electrodes indicated by peaks A-C: (A) $\mathrm{PbSO}_{4} \rightarrow \mathrm{PbO}_{2}$ (B) $\mathrm{PbSO}_{4} \rightarrow \mathrm{Pb}$ and (C) $\mathrm{H}_{2}$ evolution. On increasing the number of cycles, the peak potential has not change.

Figure 5 shows the first-cycle charge-discharge voltage profiles of $\mathrm{PbO}$ electrode at a current density of $1 \mathrm{~A} \mathrm{~g}^{-1}$. It exhibits a similar profile with two solpe voltage ranges and two voltage plateaus, and $i R$ drop $(\Delta V)$. The slopes and plateaus are attrubuted to the capacitive components: (1) ions separation in double layer regions of carbon in nanocomposites and (2) charge transfer reaction of faradaic regions of electrode materials, respecively. A sudden voltage drop represents the voltage change due to some complex polarization and internal resistance of battery system. The nanostructured $\mathrm{PbO}$ exhibit a high capacity and long cycling life. A reversible capacity of 84 $\mathrm{mAh} \cdot \mathrm{g}^{-1}$ sustains after discharging/charging for 20 cycles (Figure 6).

\section{Conclusion}

The nano-structured $\mathrm{PbO}$ as an anode material for lead acid batteries were fabricated via a simple precursor-controlled thermolysis method. The nanomaterials exhibited a reversible capacity of $140 \mathrm{mAh} \mathrm{g}^{-1}$ on the first cycle. It was believed that the block shape structure was responsible for the good electrochemical properties of the $\mathrm{PbO}$ anodes. The present finding offered a facile and inexpensive pathway to synthesize $\mathrm{Pb}$-based materials with good electrochemical performance for lead acid batteries.

\section{References}

D. Pavlov,G. Petkova,M. Dimitrov,et al. (2000). "Influence of fast charge on the life cycle of positive lead-acid battery plates." J. Power Sources. 87(1-2): 39-56.

H. Yeh,C. C. Wan and J. S. Chen. (2001). "Physical and electrochemical characterization of $\mathrm{PbO}_{2}$ electrode 
prepared at different $\mathrm{H}_{2} \mathrm{SO}_{4} / \mathrm{H}_{2} \mathrm{O} / \mathrm{PbO}$ ratios.”. J. Power Sources. 101(2): 219-225.

J. S. Chen. (2005). "Effect of $\mathrm{Na}_{2} \mathrm{SO}_{4}$ additive in positive electrodes on the performance of sealed lead-acid cells for electric scooter applications.” J. Power Sources. 90(2): 125-123.

M. Shiota,T. Kameda,K. Matsui,et al. (2005). "Electrochemical properties of lead dioxides formed on various lead alloy substrates.” J. Power Sources. 144 (2): 358-364.

M.L. Soria,J. Valeciano and A. Ojeda. (2004). "Development of ultra high power,valve-regulated lead-acid batteries for industrial applications.” J. Power Sources 136(1): 376-382.

P. Simon and Y. Gogotsi. (2008). "Materials for electrochemical capacitors.” Nature Mater. 7: 845-854.

R. De Marco,A. Lowe,M. Sercombe, et al. (2005). “An electrochemical impedance spectroscopy and scanning electron microscopy study of the influence of positive plate compression on the electrochemical behaviour of lead-acid batteries." Electrochim. Acta. 51 (10): 2088-2095.

S. Arico,P. Bruce,B. Scrosati,et al. (2005). "Nanostructured materials for advanced energy conversion and storage devicesenergy conversion and storage devices." Nature Mater. 4: 366-377.

S. M. Tabaatabaai,M. S. Rahmanifar,S. A. Mousavi,et al. (2006). "Lead-acid batteries with foam grids.” J. Power Sources. 158: 879-884.

W.H. Kao,N.K. Bullock and R.A. Peterson. (1994). US Patent. 5(322): 476

Y. Chen,B. Z. Chen,X. C. Shi,et al. (2008). "Preparation and electrochemical properties of pitch-based carbon foam as current collectors for lead acid batteries." Electrochim. Acta. 53: 2245-2249.

Z. Shi,Y.H. Zhou and C.S. Cha. (1998). "Influence of perfluorinated surfactants on the positive active-material of lead/acid batteries.” J. Power Sources. 70(2): 205-213.

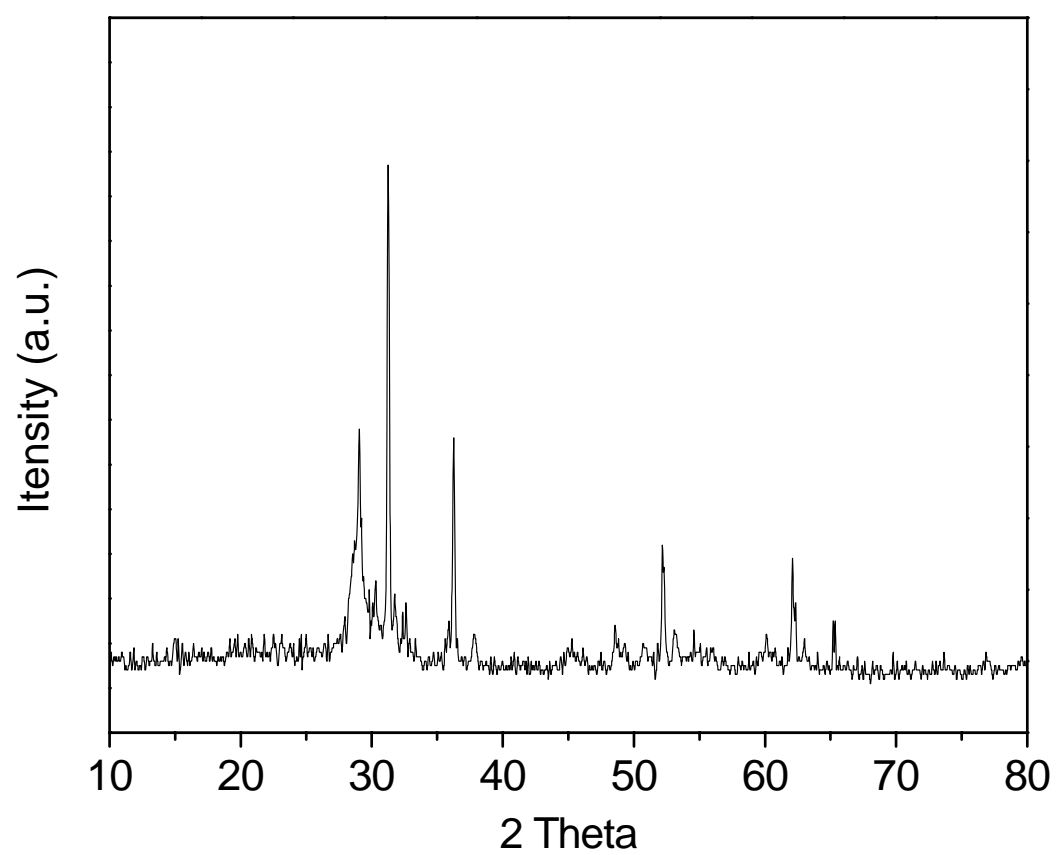

Figure 1. XRD pattern of nanostructured lead oxide 

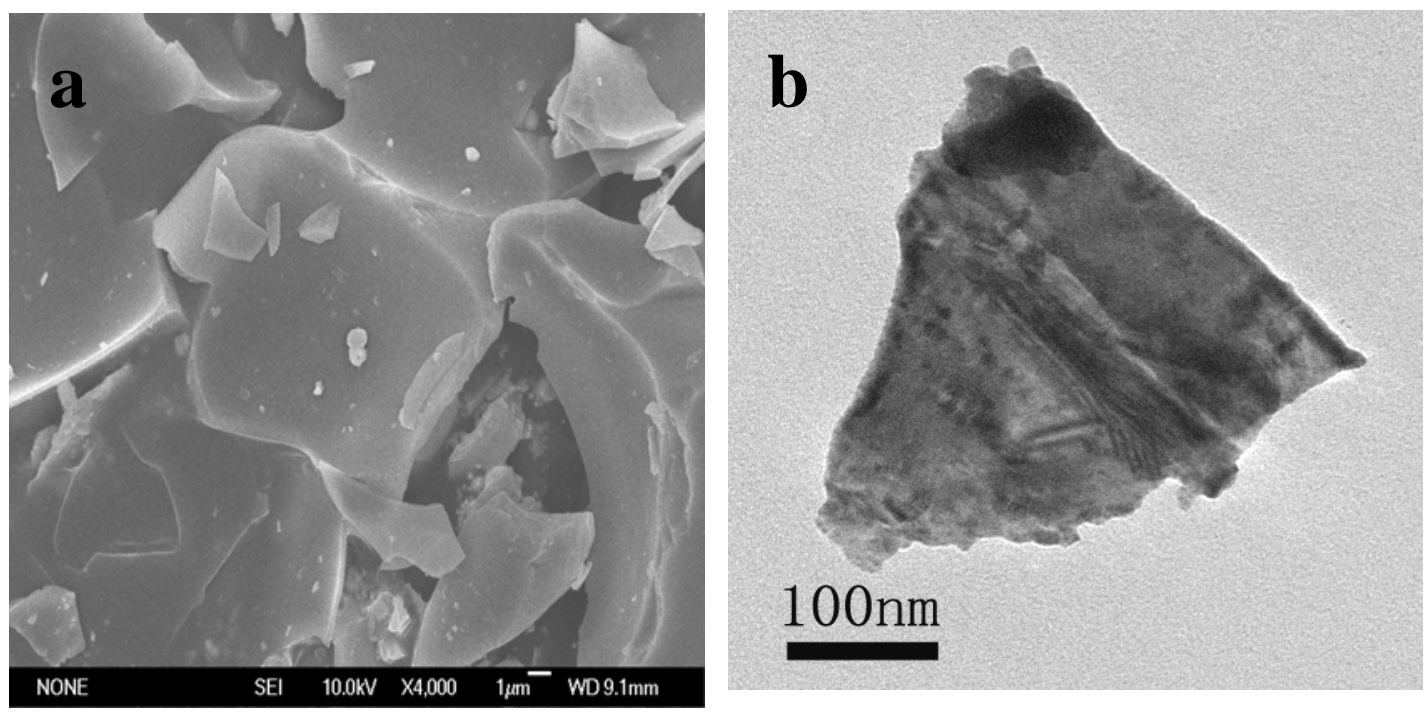

Figure 2. SEM (a) and TEM (b) image of nanostructured lead oxide

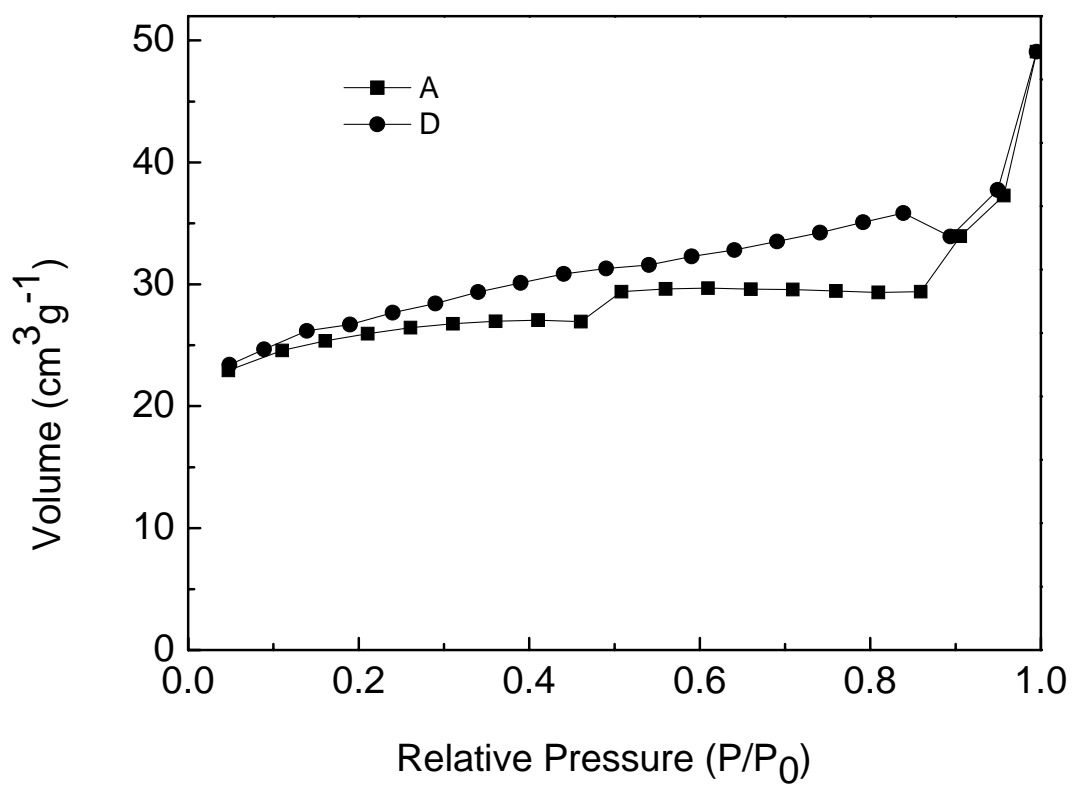

Figure 3. adsorption isotherms for the lead oxide 


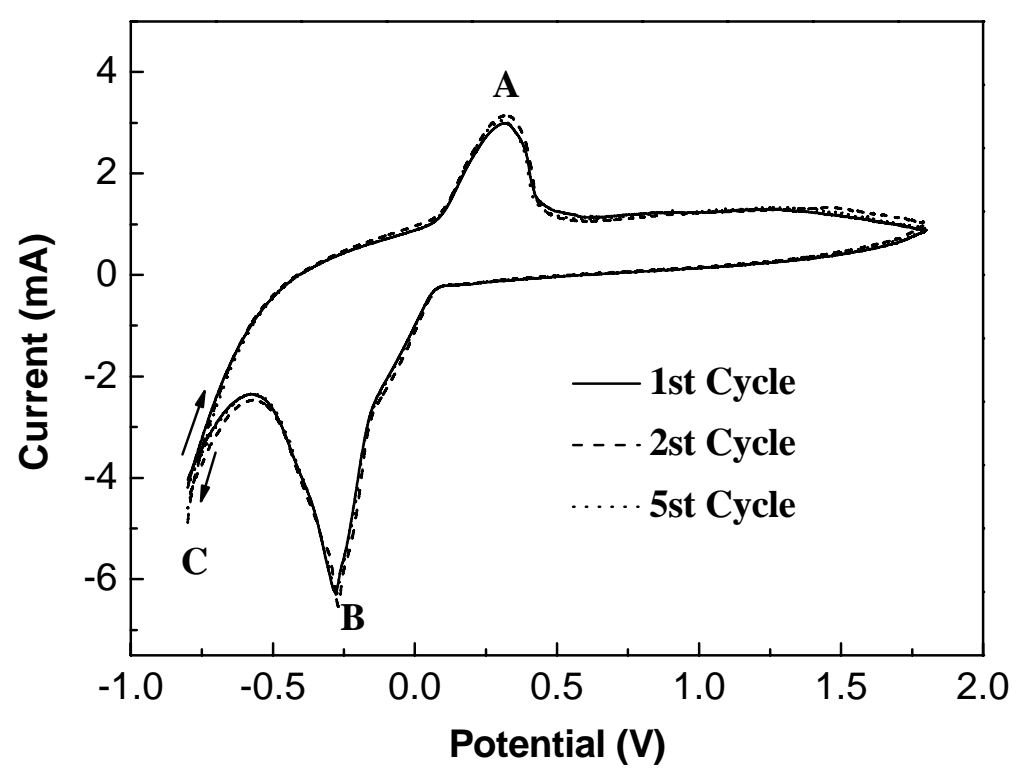

Figure 4. Cyclic voltametric curves of nanostructured lead oxide at the scan rate of $10 \mathrm{mV} \mathrm{s}^{-1}$

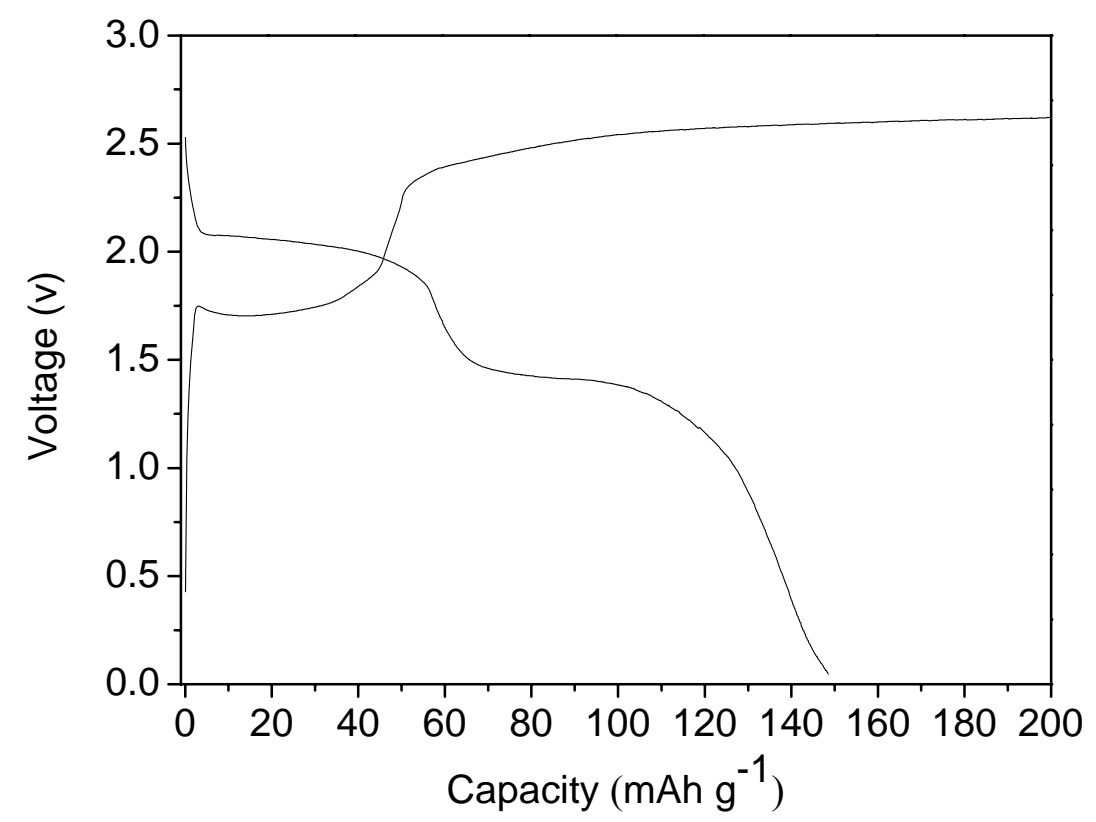

Figure 5. The first cycle charge/discharge profile of lead oxide at a constant charge-discharge current of 4mA 


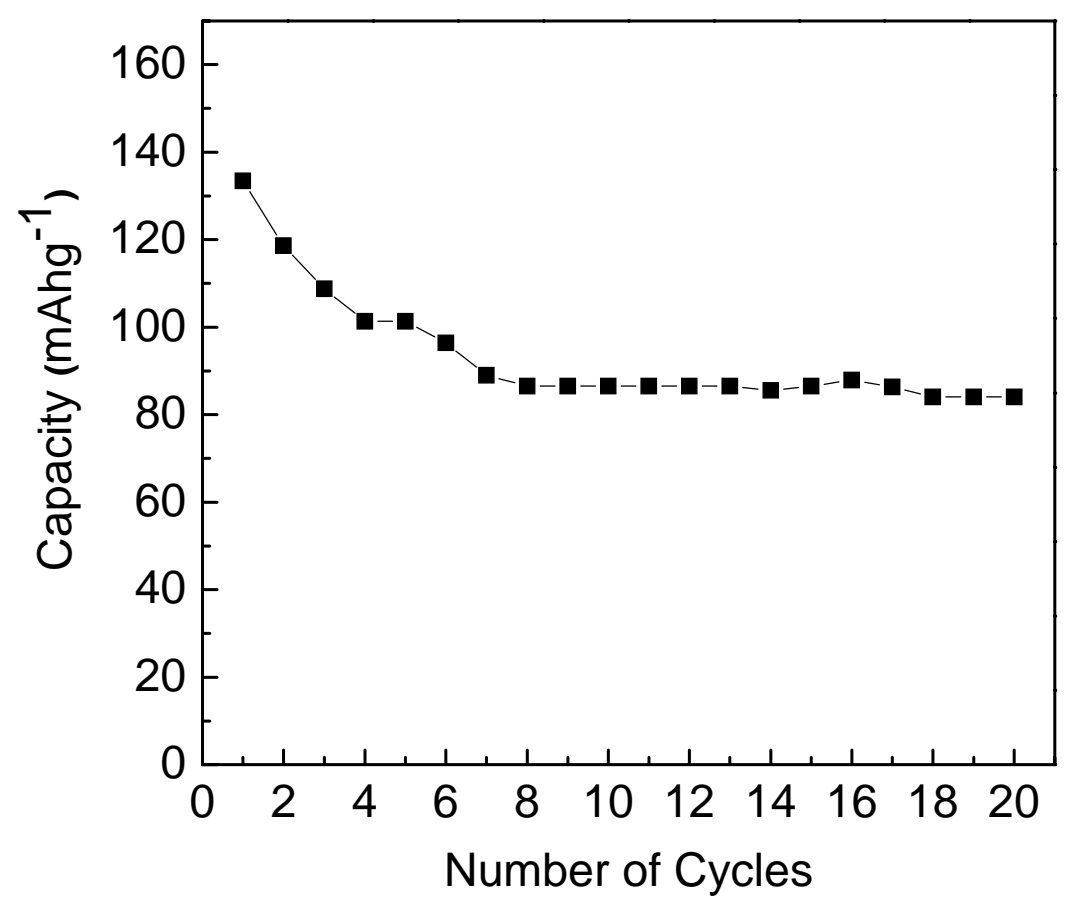

Figure 6. the discharge capacity v.s. cycle number for the nanostructured lead oxide 